
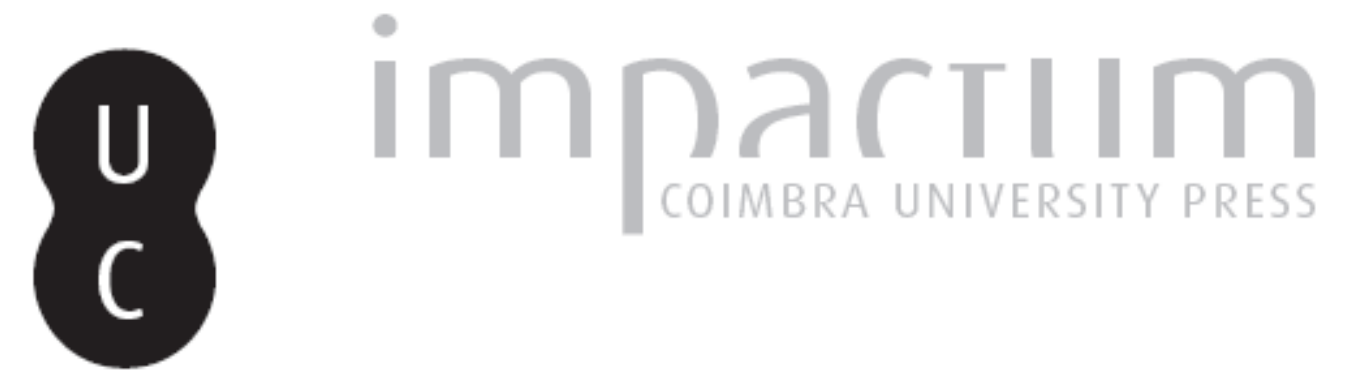

\title{
Uma colecção particular de vidros romanos
}

\author{
Autor(es): $\quad$ Nolen, Jeannette V. Smit
}

Publicado por: Imprensa da Universidade de Coimbra

URL persistente:

URI:http://hdl.handle.net/10316.2/45494

DOI:

DOl:https://dx.doi.org/10.14195/1647-8657_32_33_20

Accessed : $\quad$ 26-Apr-2023 13:01:30

A navegação consulta e descarregamento dos títulos inseridos nas Bibliotecas Digitais UC Digitalis, UC Pombalina e UC Impactum, pressupõem a aceitação plena e sem reservas dos Termos e Condições de Uso destas Bibliotecas Digitais, disponíveis em https://digitalis.uc.pt/pt-pt/termos.

Conforme exposto nos referidos Termos e Condições de Uso, o descarregamento de títulos de acesso restrito requer uma licença válida de autorização devendo o utilizador aceder ao(s) documento(s) a partir de um endereço de IP da instituição detentora da supramencionada licença.

Ao utilizador é apenas permitido o descarregamento para uso pessoal, pelo que o emprego do(s) título(s) descarregado(s) para outro fim, designadamente comercial, carece de autorização do respetivo autor ou editor da obra.

Na medida em que todas as obras da UC Digitalis se encontram protegidas pelo Código do Direito de Autor e Direitos Conexos e demais legislação aplicável, toda a cópia, parcial ou total, deste documento, nos casos em que é legalmente admitida, deverá conter ou fazer-se acompanhar por este aviso.

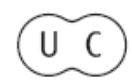




\section{UNIVERSIDADE DE COIMBRA \\ FACULDADE DE LETRAS}

\section{CONIMBRIGA}

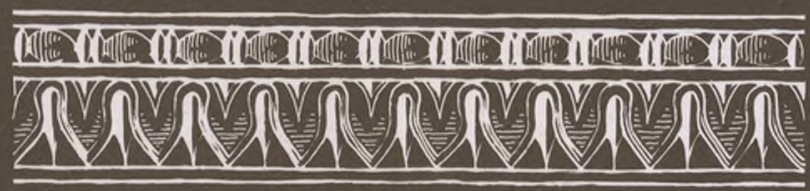

VOLUMES XXXII-XXXIII-1993/94 
JEANNETTE V. SMIT NOLEN

Investigadora da Associação Cultural de Cascais

\section{UMA COLECÇÃO PARTICULAR DE VIDROS ROMANOS}

«Conimbriga» XXXII-XXXIII (1993-1994), p.321-332

RESUMO: A A. apresenta uma pequena colecção de seis vasos romanos de vidro.

Trata-se de peças quase todas de fabrico do Médio Oriente, entre as quais o n. ${ }^{\circ} 3$ é de interesse especial. A mesma colecção pertencem mais cinco artefactos diferentes: duas ligulae de bronze, provavelmente também da época romana, um machado dos finais da Idade do Bronze e, finalmente, dois aryballoi corintios.

SUMMARY: The author presents a small collection of antiquities, including six Roman glass vessels which were studied in detail. They are mostly of Eastern Mediterranean manufacture; $\mathrm{n}^{\circ} \mathbf{3}$ is an item of special interest. A further two bronze ligulae, presumably also from the Roman period, a bronze axe typical for the late bronze age of Northern Portugal, and two late Corinthian aryballoi are merely mentioned and catalogued without further comments. The artefacts were part of the well known collection of the Duke of Palmeia, most of which was received as gifts from foreign dignitaries in the beginning of this century. They now belong to Dr. João Gonçalo de Amaral Cabral and will be donated to the archaeological museum of the Fundação da Casa de Bragança in Vila Viçosa (Portugal). 
(Página deixada propositadamente em branco) 


\title{
UMA COLECÇAO PARTICULAR DE VIDROS ROMANOS *
}

\author{
Gostaríamos de oferecer este pequeno estudo \\ ao Dr. João Manuel Bairrão Oleiro como prova de \\ gratidão por nos ter introduzido ao mundo da arqueo- \\ logia portuguesa.
}

Apresentaremos um núcleo de peças que fazia parte da antiga colecção do Duque de Palmeia. Este foi, provavelmente na sua maioria, oferecido ao Duque e/ou à Duquesa, entre outros durante umas viagens ao Médio Oriente no princípio do século. Contudo, algumas das peças, entre elas possivelmente o machado n. ${ }^{\circ}$, foram compradas no mercado na mesma altura. Trata-se de uma colecção muito eclética, envolvendo antiguidades de várias origens e diversas épocas. $\mathrm{O}$ conjunto agora exposto é da propriedade do Dr. João Gonçalo de Amaral Cabral e destina-se ao Museu Arqueológico do Paço Ducal, em Vila Viçosa. Aquele museu será, então, enriquecido com estas peças em muito bom estado de conservação.

Trata-se de um núcleo de seis vasos de vidro romano que estudamos em pormenor, enquanto que mais cinco artefactos pertencentes ao mesmo conjunto, ou seja duas ligulae e um machado de bronze, além de dois aryballoi corintios, serão apenas mencionados. Dois chauabtis egípcios, que também fazem parte deste núcleo, já foram publicados por Dr. Luís Manuel de Araújo (O.

* Manifestamos ao Dr. João de Amaral Cabral o nosso mais vivo reconhecimento por nos ter confiado a publicação desta sua colecção.

0) ARAúJo (L.M.), «Dois Chauabtis numa colecção privada portuguesa», Hathor, Estudos de Egiptologia, 1991, pp. 15-23. 
1

De Balsa existe um copo muito semelhante ao nosso n. ${ }^{\circ}$ 1. Trata-se de um copo do tipo Isings 32 que aí datámos de meados do século I a meados do II $\left(^{2}\right)$. Porém, na nossa publicação do vaso de Balsa, também apontámos para achados paralelos de Tipasa de contextos arqueológicos ainda no século III.

A decoração de depressões parece ser derivada de antecedentes metálicos. Igualmente aparece na cerâmica, por exemplo, de «paredes finas» e terra sigillata clara $Q$ ). As grandes depressões, correntes no século I, constituem uma degeneração das dedadas pequenas e múltiplas mais antigas. Estas estão já documentadas em «paredes finas» de Cosa duma lixeira datada do segundo ou terceiro quartel do século I a.C. $\left({ }^{4}\right)$, enquanto na época de Cláudio-Nero já se mostram sensivelmente mais largas neste tipo de cerâmica ${ }^{5}$ ). Um copo de vidro de Herculano, por isso com terminus ante quem de $79 \mathrm{~d}$. C., mostra oito ou nove depressões alongadas e altas $\left({ }^{6}\right)$. Em vidro, este tipo de decoração é especialmente frequente na bacia mediterrânica durante a segunda metade do século I até aos meados do século II (7), sendo menos encontrado nas províncias do Norte do Império. De Tipasa provêm exemplares especialmente análogos, os primeiros em conjunto com sigillata aretina, os últimos de sepulturas que datam da época de Lucius Verus ou seja dos finais de século II $\left({ }^{8}\right)$. Sendo assim, podemos pensar numa origem mediterrânica para a peça. Exemplares mais requintados deste tipo têm um ou mais pequenos pés de argola, ou, em contrapartida, o fundo levantado e apertado com turquezes, formando assim um pé relativamente alto.

\section{2}

A propósito de um duplo unguentàrio no Royal Ontario Museum, Hayes observa que este tipo de vasilhas múltiplas são encontradas ${ }^{*}$ i

(2) ISINGS, pp. 46-47; NoLEN, n. ${ }^{\circ}$ vi-24, pp. 173, 189, Est. 36.

(3) Nolen, n. ${ }^{\circ}$ sc-1, p. 98 , Est. 19.

$\left({ }^{4}\right)$ Moevs, n. ${ }^{\circ}$ s 132-133, pp. 86-87, Est. 12, 62.

(5) Moevs, n. ${ }^{\circ} 434$, pp. 238-239, Est. 46, 86.

$\mathrm{i}^{6}$ ) HörICHT, n. ${ }^{\circ} 67$ (E2352), p. 40, Est. XIV, XXVIII.

(7) Podemos citar alguns exemplares parecidos: BARKóCZI, n. ${ }^{\circ} 120$, p. 88, Est. XI, XILXXIV; PlesniCar-GeC, n..$^{\circ} 8$ da sepultura 323, p. 198, Est. LXXXIII, n. ${ }^{\circ} 10$ da sepultura 332, p. 200, Est. LXXXVI e n. 7 da sepultura 927, p. 265, Est. CLXXXI; fora de estratigrafía.

(s) LANCEL, n. ${ }^{\text {s }}$ 144-158 do tipo 22a, pp. 18, 76-82, Est.VIII. 
durante o Baixo Império em diversas variantes ou feitios no âmbito sírio-palestiniano ${ }^{(9}$ ). $\mathrm{O}$ autor data um exemplar daquele museu da primeira metade do século IV $\left(10^{*}\right)$, enquanto a cronologia tradicionalmente apontada é dos séculos IV e V Todavia, na Panónia, este tipo de unguentàrio está documentado no período b, ou seja, dos anos c. 167 até c. $270(\mathrm{n})$. Consequentemente, temos que incluir, ao menos, o século III na cronologia do nosso unguentàrio. No museu de Newark, encontram-se várias peças semelhantes, das quais particularmente os n. ${ }^{\text {s }} 484$ e 487 são parecidos com o da presente colecção. Infelizmente, nenhum deles foi achado em contexto cronológico documentado (12).

3

Garrafas ou frascos soprados em moldes - dos quais o n. ${ }^{\circ} 3$ constitui uma variante - foram bastante comuns nos séculos III e IV; contudo, a cronologia pormenorizada das variantes ainda não foi estabelecida $\left({ }^{13}\right)$. Porém, não há dúvida sobre a sua origem do Este da bacia mediterrânica. A peça pertence, de certeza, ao grupo citado por Haevernick a propósito de um «objecto» na colecção Oppenländer decorado com quatro máscaras $\left({ }^{14}\right)$. Todavia, a autora não documenta um frasco bem igual ao exemplar da colecção do Dr. Amaral Cabral.

Haevernick, ao publicar este «objecto», cita mais outro, proveniente da Síria, este com apenas duas máscaras. A autora sugere que se trata de lucernas ou boiões, mas parecem-nos, antes, frascos com a parte superior derretida pelo calor, talvez resultante das cinzas do enterramento de incineração do qual possivelmente fizeram parte. Ambos têm várias pequenas depressões quadradas onde a autora supõe ter existido uma aplicação decorativa.

A autora cita outros frascos decorados com máscaras do mesmo tipo em Varsóvia, Neuburg, Viena, Jerusalém, no Louvre e, além disso, menciona mais um na colecção Ray Winfield Smith, em Corning N.Y.

(9) HAYES, p. 83.

(10) HAYES, n. ${ }^{\circ} 358$, p. 101, Est. 28.

(") BARKócZI, n. ${ }^{\circ} 375$, pp. 22, 163, Est. XXXIV, XCIII.

(12) AUTH, n. ${ }^{\text {os }} 484$ e 487, pp. 224, 225.

(13) Auth, n. ${ }^{\circ} 74$, p. 74.

(14) Agradecemos à Doutora Sophia M.E. Van Lith o ter chamado a nossa atenção para este paralelo; Cf. HAEVERNICK.

Conimbriga, 32-33 (1993-1994), 321-332 
A última é a única peça de secção quadrada (15). Apenas um destes exemplares tem quatro máscaras, tal como o «objecto» da colecção Oppenländer; os outros foram decorados com apenas duas máscaras. E em todos as máscaras são iguais às do nosso frasco.

As máscaras de todas as peças publicadas mostram laços à volta da testa, além de orelhas de tamanho exagerado. Estas orelhas parecem ser mais evidentes no presente exemplar. A autora levanta dúvidas se se trata de orelhas ou talvez do cabelo ou até das aselhas do laço. Haevernick compara as máscaras com outras, aliás protótipos, de duas taças encontradas em sepulturas do século IV. Não toma posição sobre a questão da máscara e, por isso, os frascos podem ser atribuídos a um ambiente sassânida, copta, árabe ou, até, iraniano.

A autora sugere uma função apotropaica para as máscaras, que, em conjunto com uma asa em forma de um animal não identificado que ainda se conserva numa das garrafas, pode atribuir uma tal função às peças.

$\mathrm{O}$ frasco $\mathrm{n} .^{\circ} 3$ ainda guarda o resto de um fio de vidro à volta do gargalo, tal como todos os frascos citados por Haevernick. Porém, esta linha em espiral continua-se no ombro, enquanto que na base existem uma linha ondulada e motivos tipo flor-de-lis entre as máscaras. São testemunhos estes de decorações feitas depois da moldagem e que não acontecem nas outras peças publicadas. Toda esta decoração é visível na superfície do vidro e parcialmente mostra a mesma corrosão. Todavia, no bojo, nalguns lugares, ainda se conserva a superfície lustrosa em contraste com o resto da peça.

Não nos é possível explicar a origem desta decoração. No entanto, os motivos podem reflectir os apliques sugeridos por Haevernick para os dois "objectos" citados. Será derivada da descolagem de apliques fixados posteriormente ao fabrico do próprio vaso? Assim, teríamos de supor que desapareceram um fio de vidro em espiral do gargalo e ombro, outro ondulado da base e dois apliques pré-moldados, sem deixar qualquer outro resto senão uns sítios de vidro lustroso. Além disso, a porção lustrosa desta decoração indica a sua descolagem em parte depois de a superfície sofrer a corrosão agora evidente. Ou será que eventuais restos foram retirados durante o restauro moderno que nos parece ter sido muito bem sucedido? Foi-nos impossível saber onde, quando ou por quem este restauro foi efectuado; contudo, de

(15) Sмith (R. W .), Glass from the Ancient World, n. ${ }^{\circ}$ 416, p. 209. 
modo nenhum podemos admitir que aquele bom técnico haja retirado algum testemunho da decoração ainda presente na altura.

$\mathrm{O}$ frasco parece ter sido soprado em molde duplo, enquanto Haevernick julga que os seis descritos por ela foram todos feitos em três partes, duas partes moldadas para o corpo e uma, apenas modelada, do fundo. As garrafas mostram uma secção oval e não redonda; os lados, onde as duas metades foram ligadas, parecem nitidamente achatados.

Infelizmente, nenhuma destas peças tem proveniência exacta e/ou cronologia documentada, de maneira que é impossível assegurar-lhes a cronologia exacta. Porém, uma data nos séculos III ou IV será a mais indicada.

Vários autores, ao publicarem peças com decoração semelhante, sugeriram cronologias desde 3000 até 550 a. C. $\left({ }^{16}\right)$, o que nos parece completamente fora de questão. Enquanto que von Saldem levanta a possibilidade - muito provável, a nosso ver - de se tratar de falsificações $\left({ }^{17}\right)$.

Estes frascos têm os seus antecedentes já na segunda metade do século I encontrados, por exemplo, em Herculano $\left({ }^{18}\right)$. Naquela época, os ateliers da Síria produziram pequenas garrafas hexagonais, igualmente sopradas em molde, com decoração variada; aliás, as máscaras foram sempre raras. A decoração encontrada abrange muitos temas: uma colecção importante deste tipo de frascos em Newark mostra decorações de motivos vegetais, como flores e frutas incluindo romãs e cachos de uvas, grinaldas de folhas de oliveira, até elementos arquitectónicos e motivos da vida diária, como ânforas $\left({ }^{19}\right)$. São todos considerados de fabrico oriental; apenas um pequeno grupo, este sempre decorado com máscaras, é considerado de fabrico itálico ${ }^{(20)}$. No entanto, o tema de duas ou, às vezes, quatro caras ou máscaras era o mais vulgar nas peças mais tardias.

\section{4 e 5}

As bilhas n.os 4 e $\mathbf{5}$ podem ser confrontadas com um grupo de vasos em Trier da forma Trier 124a, classificada pela autora do tipo

(16) HAEVERNICK, n. 2.

(17) SALDERN, pp. 309-310.

(,8) HöRICHT, n. ${ }^{\circ} 104$ (E1238), p. 52, Est. XVII, XXXIII.

(19) AUTH, n. ${ }^{\text {s }}$ 321-330, pp. 197-199.

(20) LighTFOOT, pp. 11-21.

Conimbriga, 32-33 (1993-1994), 321-332 
Isings 120a $\left({ }^{21}\right)$. Estas bilhas geralmente datam dos finais do século III e do decorrer do século seguinte $\left({ }^{22}\right)$. Naquela época, bilhas bicolores em várias gamas de cores encontram-se em muitas estações arqueológicas. Um exemplar de vidro azul com asa e decoração em vidro opaco de cor verde amarelada foi encontrado numa sepultura, em Bona, com terminus post quem no ano de 295(23). Contudo, os nossos exemplares não mostram o pé de argola vulgar para os tipos Trier 124a ou Isings 120a. Os seus fundos simples fazem-nos pensar num fabrico regional, afastado dos grandes centros de produção vítrea mais requintada. No nosso entender, temos que procurar uma proveniência no Este da bacia mediterrânica; achados semelhantes, como os da Panónia ou Jalame, parecem ser do mesmo ambiente artesanal (24). Ainda que em Jalame bilhas de asa azulada sejam raras, o esquema de decoração com fio de vidro azul aparece com certa frequência na segunda metade do séc. IV (25).

\section{6}

O unguentàrio n. ${ }^{\circ} 6$, de uma forma baixa e entroncada, é considerado de fabrico egípcio; mesmo assim, não é muito vulgar no Médio Oriente e é raro na Europa continental. Encontra paralelos, entre outros, em Trier, Aquileia, Panónia e Karanis $\left({ }^{26}\right)$. O espécime da Panónia foi datado de finais do século I ou dos inícios do século seguinte, enquanto os dois exemplares de Trier foram encontrados numa sepultura do século II, mais provavelmente da segunda metade. Outros dois, encontrados em Karanis, provêm de uma casa datável de fins do século III ou inícios do século seguinte. Contudo, Harden considera que o tipo não ultrapassa o século III $\left({ }^{27}\right)$. Finalmente, Calvi, ao publicar vários

(21) GOETHERT-POLASCHECK, tipo 124a, n. ${ }^{\text {os }}$ 1281-1300, pp. 209-213, Est. 20, 23, 24, 69-70.

(22) ISINGS, tipo 120a, pp. 149-150.

(23) FollmanN-SChUlTZ, n. ${ }^{\circ}$ 196, p. 63, Est. 23.

${ }^{(24)}$ BARKóczi, n. ${ }^{\circ} 395$, pp. 22, 168, Est. XXXVI, XCIV; WeINBERg, n. ${ }^{\circ}$.s 214, 216, p. 64-67, fig. 4-27, Est. 3C e n. ${ }^{\circ}$.s. 217-228, p. 67-68, fig. 4-28, Est 4-10.

${ }^{(25)}$ Weinberg, p. 82, Est 3C.

${ }^{(26)}$ Goethert Polascheck, tipo 74, n. ${ }^{\text {os }}$ 664, 665, sepultura 158, pp. 121, 300, Est. 53; CALVI, n. ${ }^{\circ} \mathrm{s} 294,295$, pp. 140, 144, Est. 20-4, 5; BARKóczI, n. ${ }^{\circ}$ 262, 263 do tipo 104, pp. 20, 130, Est. XX, LXXXII; HARden, n. ${ }^{\circ}$ s 815-818, p. 266, 274-275, Est. $\mathrm{X}, \mathrm{XX}$.

(27) HARDEN, p. 266.

Conimbriga, 32-33 (1993-1994), 321-332 
destes balsamários de Aquileia, nota que exemplares de proveniência oriental são muito mais antigos que os feitos naquele local, os quais o autor também data do século III $\left({ }^{28}\right)$. Por isso, sem saber a origem da peça da presente colecção, é impossível precisar a cronologia exacta. Apenas nos é possível indicar o período desde os finais do século I até aos finais do século III para o balsamário em questão, considerando-o mais provavelmente deste último século.

7 e 8

Duas sondas em bronze, n. ${ }^{\text {s }} 7$ e 8 , constituem objectos de toilette diária, ou, possivelmente, equipamento cirúrgico. Estes instrumentos, dos quais paralelos muito semelhantes ainda estão em uso hoje em dia, são impossíveis de datar com qualquer grau de confiança; porém, as peças parecem-nos da época romana. Em Portugal, uma sonda parecida ao nosso n. 7 foi encontrada em Conimbriga, num estrato da construção do foro flávio $\left({ }^{29}\right)$, outra na villa romana de São Cucufate numa camada cuja cronologia não está especificada $\left({ }^{30}\right)$. De Verulamium podemos citar um "instrumento" incompleto, que, aliás, parece a combinação de uma espátula e um misturador, proveniente de uma camada dos anos 75-105 d. C.( $\left.{ }^{31}\right)$.

9

Mais provavelmente de origem portuguesa é o machado de alvado em bronze (32). Com apenas uma "aselha", a peça pode ser inserida no tipo 41 A da tipologia de Monteagudo( $\left.{ }^{33}\right)$. Este tipo de machados é especialmente encontrado no Noroeste de Portugal, mas também existe um exemplar português da Estremadura e outro, este espanhol, de Pontevedra. A peça data da Idade de Bronze Final III, ou seja de $1000 / 900$ a 750/700 a. C. Servia para cortar, por exemplo, lenha, embora que o seu uso como arma também não seja de excluir $\left({ }^{34}\right)$.

(28) Calvi, n. ${ }^{\text {os } 294, ~ 295, ~ p p . ~ 140, ~ 144, ~ E s t . ~ 20-4, ~} 5$.

$\left.{ }^{29}\right)$ Fouilles de Conimbriga, VII, n. ${ }^{\circ} 272$, pp. 146-147, 149, Est. XXXVI.

$\left.{ }^{30}\right)$ Ponte, n. ${ }^{\circ} 46$, p. 140, 143, Est. III.

(31) Frere, n. ${ }^{\circ} 71$, p. 124, fir. 35.

(32) Devemos ao Dr. Fransisco Alves a identificação e descrição deste peça.

(33) Monteagudo, tipo 41 A, p. 242-243, n. ${ }^{\text {os }}$ 1687-1689, Est. 117.

(34) Monteagudo, p. 242.

Conimbriga, 32-33 (1993-1994), 321-332 


\section{0 e 11}

Nesta pequena colecção ainda existem dois aryballoi, n.os $\mathbf{1 0}$ e $\mathbf{1 1}$ de fabrico corintio tardio. Os motivos pintados são bastante simples e de repetição, enquanto que a forma das duas peças também pertence ao estilo corintio já desenvolvido de c. 600 a c. 550 a. C. $\left({ }^{35}\right)$.

\section{CATÁLOGO}

1 Copo decorado com quatro depressões.

Tipo Isings 32, bordo de arestas em forma de «S».

Vidro de boa qualidade, ligeiramente tingido de verde sombrio; picado e com corrosão acastanhada.

Diâmetro do bordo $88 \mathrm{~mm}$, altura $95 \mathrm{~mm}$. Inteiro.

Cronologia: Finais do século I até ao decorrer do século II.

2 Unguentàrio duplo.

Vidro de boa qualidade, de cor verde gelo; com irisão incipiente e corrosão.

Altura $120 \mathrm{~mm}$. Inteiro.

Cronologia: Século III até aos meados do século IV.

3 Frasco com decoração moldada.

Vidro de qualidade média, de cor acastanhada manchada de verde e roxo; riscado. Decoração moldada de duas máscaras no bojo, linhas em espiral no gargalo, ombro e parte superior do bojo. Desenhos figurativos (?) entre as máscaras e uma linha ondulada na base. Restos de um fio de vidro no gargalo.

Altura $130 \mathrm{~mm}$. Restaurado.

Cronologia: Séculos III ou IV ou moderno.

4 Bilha de asa azul.

Qualidade do vidro de impossível verificação devido à corrosão acastanhada. Vidro muito levemente tingido de verde gelo. Asa e fio de vidro à volta da sobarba de vidro azul cobalto.

O bojo foi soprado em molde e mostra uma decoração de reentrâncias pequenas em quatro fiadas horizontais.

Altura $96 \mathrm{~mm}$. Inteira.

Cronologia: Séc. IV (segunda metade ?).

5 Bilha decorada com espiral em vidro verde gelo.

Vidro de qualidade boa, ligeiramente tingido de verde sombrio. Superfície baça e irisão leve.

(35) CoOK, pp. 55-56, Est. 10-B.

Conimbriga, 32-33 (1993-1994), 321-332 
Decoração de uma asa e fio de vidro em espiral à volta do colo de vidro verde gelo. Fundo alteado com marca do pontel.

Altura $103 \mathrm{~mm}$. Inteira, o gargalo está deformado pelo calor.

Cronologia: Séc. IV (segunda metade ?).

6 Balsamário do tipo Karanis Class XIII-C.

Vidro de qualidade média, de cor verde gelo; com corrosão e irisão.

Diâmetro máximo $62 \mathrm{~mm}$, altura $67 \mathrm{~mm}$. Inteiro.

Cronologia: (Finais do século I até aos finais do) século III.

7 Lígula em bronze.

Espátula e misturador arredondado.

Decoração de linhas horizontais gravadas.

Corrosão estável.

Comprimento $130 \mathrm{~mm}$. Inteira.

Cronologia: Indeterminável.

8 Lígula ou misturador (?) em bronze.

Parcialmente (a pega ?) de secção quadrada com $6 \mathrm{~mm}$ de lado.

Decoração de uma linha gravada em espiral na parte de secção quadrada.

Forte corrosão.

Comprimento preservado $138 \mathrm{~mm}$. Incompleto das duas extremidades.

Cronologia: Indeterminável.

9 Machado de alvado com acabamento de seç̧ão rectangular e um único anel ("aselha") lateral, de gume estreito.

Comprimento total, $126 \mathrm{~mm}$, comprimento do gume $32 \mathrm{~mm}$.

Estado de conservação muito bom.

Cronologia: Idade de Bronze Final III (1000/900 - 750/700 a. C.).

10 Aryballos corintio.

Fundo ligeiramente achatado.

Decoração pintada em preto: uma rodela de folhas no ombro e seis linhas horizontais no bojo.

Altura $52 \mathrm{~mm}$.

Cronologia: c. 600 - 550 a. C.

11 Aryballos corintio.

Ombro ligeiramente carenado.

Decoração pintada em preto, agora descolorado para castanho: um padrão de folhas encaixadas.

Altura $49 \mathrm{~mm}$.

Cronologia: c. 600 - 550 a. C. 


\section{BIBLIOGRAFIA}

Alarcão (J. de), Delgado (M.), Mayet (F.), Alarcão (A. Moutinho) e Ponte (S. da) Fouilles de Conimbriga VI, Céramiques Diverses et Verres, Paris, 1976. ( = Fouilles de Conimbriga, VI.)

Alarcão (J. de), Étienne (R.), Alarcão (A. Moutinho) e Ponte (S. da), Fouilles de Conimbriga, VII, Trouvailles Diverses et Conclusions Générales, Paris, 1979. ( = Fouilles de Conimbriga, VII.)

AUTH (S.H.), Ancient Glass at the Newark Museum, Newark, 1976.

BARKÓCZI (L.), Pannonische Glasfunde in Ungarn, Budapeste, 1988.

CALVI (M.C.), I vetri romani del Museo di Aquileia, Aquileia, 1968.

CooK, R.M., Greek Painted Pottery, Chicago, 1960.

FolLMANN-SCHULTZ, Die römischen Gläser aus Bonn, Köln, 1988.

FREMERSDORF, Das naturfarbene (sogen, blaugrüne) Glas in Köln, Die Denkmäler des römischen Köln, Band IV, Köln, 1958.

FRERE (S.), Verulamium Excavations, I, RRCSAL, 28, Londres, 1972.

GOETHERT-POLASCHEK (K.), Katalog der römischen Gläser des Rheinischen Landesmuseums Trier, Mainz am Rhein, 1977.

HARDEN (D.B.), Roman Glass from Karanis, Ann Arbor, 1936.

HAEVERNICK (T.E.).«Beiträge zur Geschichte des antiken Glases, IV. Gefässe mit vier Masken», em Beiträge zur Glasforschung, Die wichtigsten Aufsätze von 19381981, (reedição de: Jahrbuch RGZM 7, 1960, pp. 53-60), Mainz am Rhein, 1981, pp. 84-87.

HAYES (J.W.), Roman and Pre-Roman Glass in the Royal Ontario Museum, Toronto, 1975.

HÖRICHT (A.S. SCATOZZA), I Vetri Romani di Ercolano, Ministero per i beni Culturali ed Ambientali, Soprintendenza Archeologica di Pompei, Cataloghi 1, Roma, 1986.

ISINGS (C.), Roman glass from dated finds, (Archaeologica Traiectina, (II), Groningen, 1957.

LANCEL (S.), Verrerie Antique de Tipasa, Paris, 1967.

LIGHTFOOT (C.S.), «A group of early Roman mold-blown flasks from the West», J.G.S., voi. 29,1987

Moevs (M. T. MARABINI), The Roman Thin Walled Pottery from Cosa (1948 - 1954) Memoirs of the American Academy in Rome, vol. XXXII, Roma, 1973.

Monteagudo (L.), Die Beile auf der Iberischen Halbinsel, München, 1977.

Nolen (J. U. SMIT), Cerâmicas e Vidros de Torre de Ares «Balsa», Lisboa, 1994.

PLESNICAR-GEC (L.), Severno Emonsko Grobice, The Northern Necropolis of Emona, Ljubljana, 1972.

PONTE (S. da), «Artefactos de S. Cucufate», Conimbriga, XXVI, 1987, pp. 133-165.

SALDERN (A. von), «Originals - Reproductions - Fakes», Annales du $5^{e}$ Congrès International d'Étude Historique du Verre, Prague, 6-11, juillet 1970, Liège, 1972, pp.299-318

WeINBERG (G. DAVIDSON) ed., Excavations at Jalame, Site of a Glass Factory in Late Roman Palestine, Columbia, 1988.

Conimbriga, 32-33 (1993-1994), 321-332 
EST. I
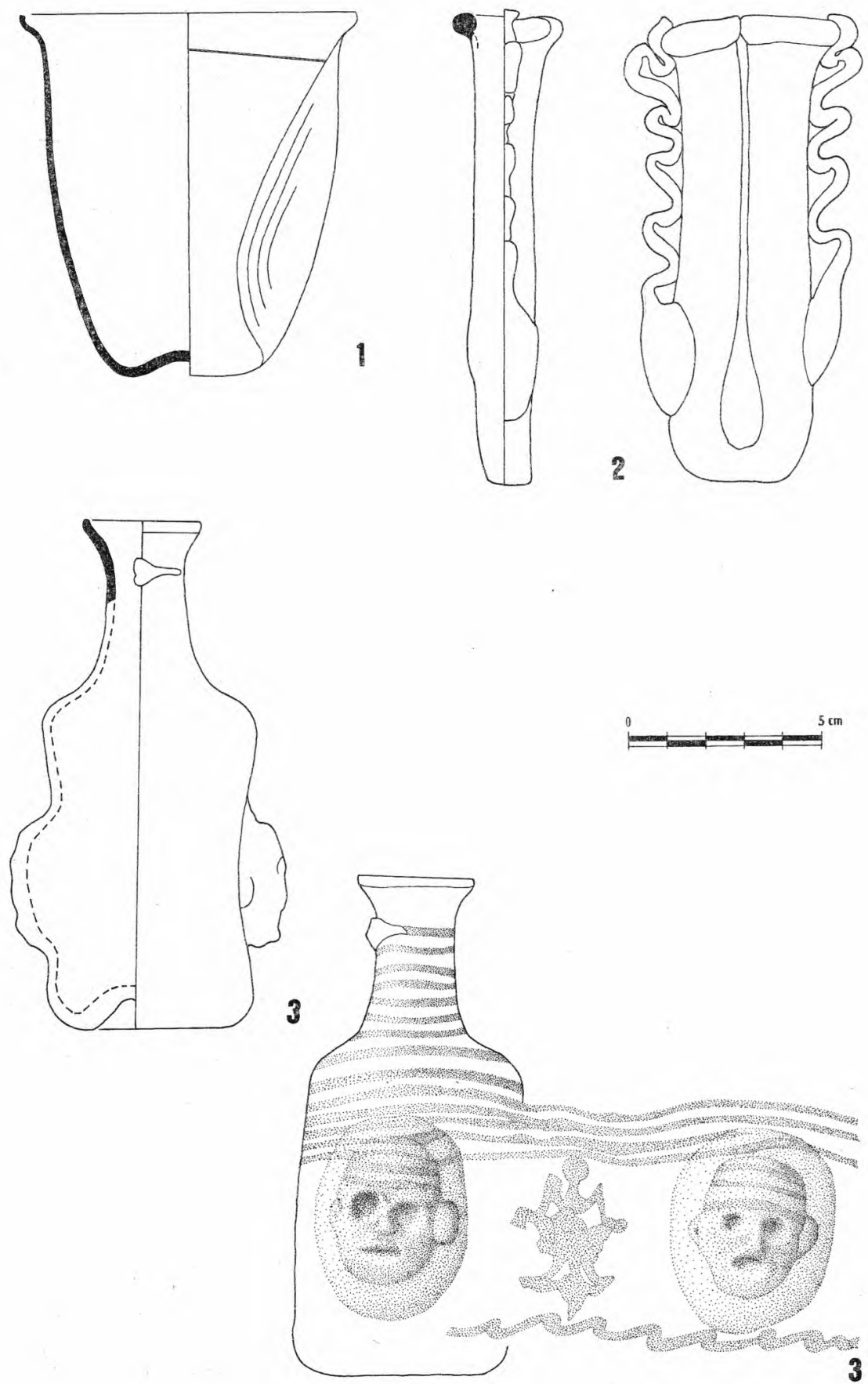


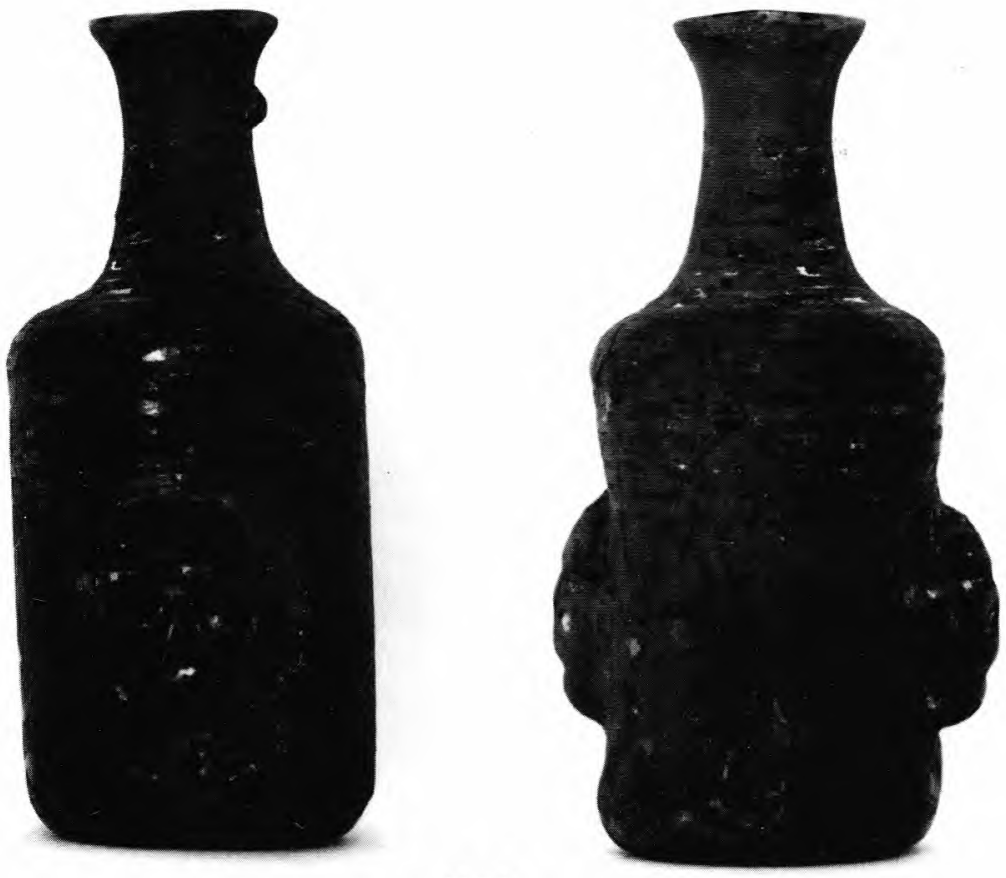

N. ${ }^{\circ} 3$
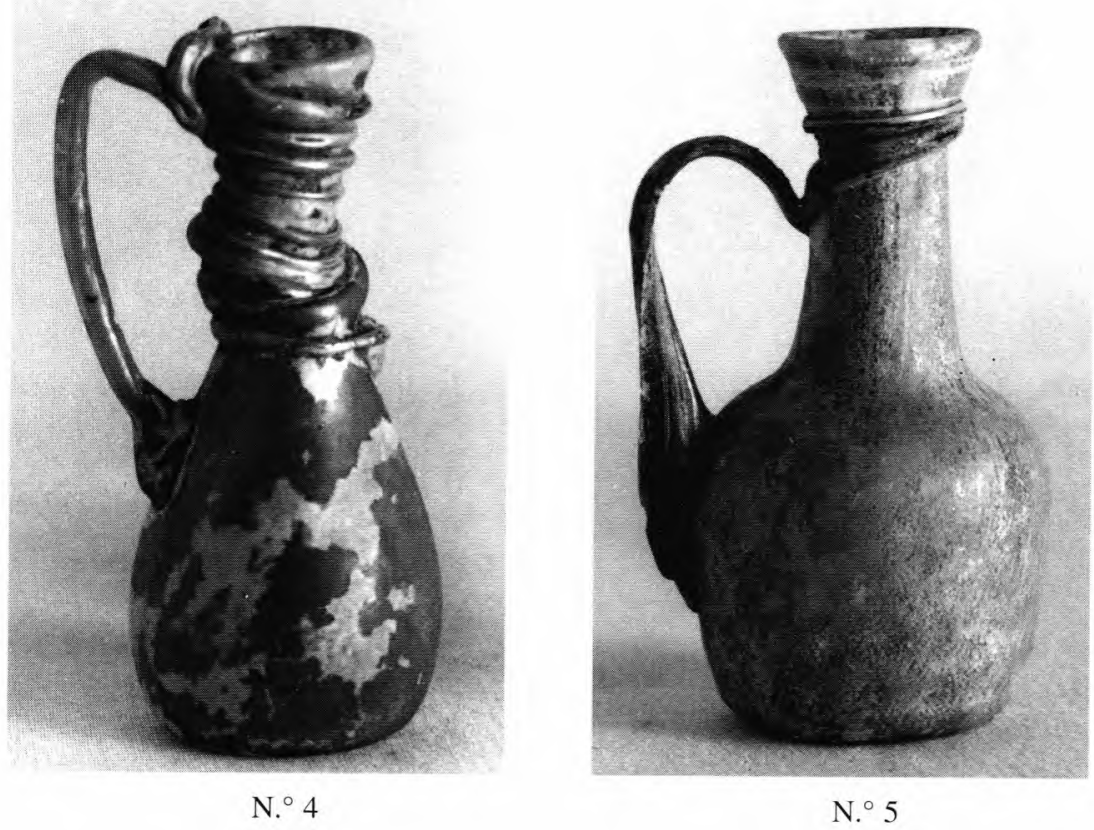


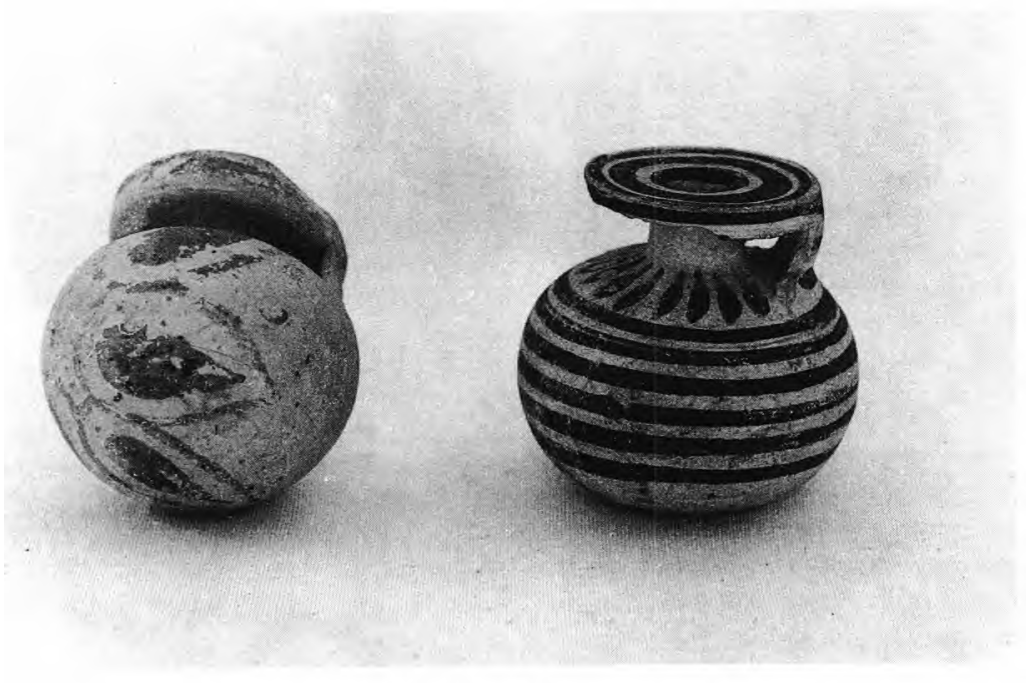

N. ${ }^{o s} 10$ e 11 